\title{
School environment as a prerequisite for acculturation of migrant children (foreign students) using School № 36, in the city of Perm, Russia, as an example
}

\author{
Elisey Chashchin ${ }^{1, *}$, Alexander Kolchanov ${ }^{2}$, Konstantin Kamyshev ${ }^{1}$ \\ ${ }^{1}$ Perm National Research Polytechnic University, 614990, Perm, Russia \\ ${ }^{2}$ School № 36, 614084, Perm, Russia
}

\begin{abstract}
Consideration of the problem of migrants in education is extremely relevant. To date, the name "multi-ethnic school" is assigned to this type of national Russian school, the contingent of which is up to $15 \%$ of the "monoethnic" students who speak Russian at an insufficient level to become the language of instruction in the school. The main result of school education for us is its compliance with the goals of the advanced development of young people. Foreign students in the process of delving into the peculiarities of the Russian language initially see it as a game and thanks to this approach find playful ways to learn. In the future, this skill is subconsciously extrapolated to the rest of their activities. They turn out to be more receptive and adaptive to the changing "rules of the game" than those who were initially immersed in its atmosphere and gradually mastered its rules. On a concrete example, it is considered how the school environment is capable of realizing the conceptual idea of multicultural education.
\end{abstract}

\section{Introduction}

Intensive migration processes in the post-Soviet states, with their associated economic and political phenomena, inevitably affect the educational sphere as well. The experience of many countries of the world shows that education today is "one of the most promising and developing industries that bring multimillion-dollar revenues" (Teterin V. I. Internationalization of higher education as a way of communication in the modern educational space (using Perm universities as an example). Problems of Modern Pedagogical Education. 2017. No. 55-11. P.234.). Therefore, consideration of the problem of migrants in education is extremely relevant.

\footnotetext{
*Corresponding author: chashin86@mail.ru
} 
The type of educational institution we are considering is the national Russian general education school, i.e. the educational organization where the Russian national educational standard is implemented. Thus, within the territory of the Russian Federation (as well as abroad) all schools where the Russian educational standard is implemented are "national Russian". In fact, all schools of the Russian Federation are either Russian national (educational standard), or multi-ethnic (up to $15 \%$ of students of different nationalities). The Russian comprehensive school has always been multiethnic, as there are more than 160 nationalities in the territory of the Russian Federation.

To date, the name "multi-ethnic school" is assigned to this type of national Russian school, the contingent of which is up to $15 \%$ of the "monoethnic" students who speak Russian at an insufficient level to become the language of instruction in the school. These are children of migrants who enter the regular national Russian school regardless of citizenship and knowledge of the Russian language. This creates a lot of problems for both children and teachers of this educational organization, which is expressed in the difficulties in the prevention and mitigation of social and language deprivation, the dialogue between cultures, the creation of the environment of the main language, the education of tolerance, etc.

The main institute of social and cultural integration of schoolchildren in the modern Russian multi-ethnic environment is a secondary school. Since the beginning of the XXI century the interest of researchers in the phenomenon of environment in connection with the problems of socialization of children and youth in our country, as well as the study of cultural processes in education in the context of its new educational paradigm has increased significantly (Ivanov A.V. the Phenomenon of the cultural environment of educational organizations in the development of children's spiritual values// Pedagogical education in Russia. 2016.№ 3.S. 200).

\section{Body part}

In this article, an option for such a general school environment is proposed, namely, the model that has been developed in School № 36 in Perm. This secondary school is located in one of the remote districts of Perm, on the outskirts of the city. This ordinary educational institution is more than sixty years old. The school is located in a special socio-cultural environment. Ethnic migrants settle in this neighborhood because of the proximity of the railway station, warehouses and wholesale depots (requiring particular and low-skilled labor), as well as the relative cheapness of housing. This part of the city is an example of a multicultural border zone, in which a balance has developed between representatives of different socio-cultural, religious and ethnic groups. This neighborhood was formed as a result of the evacuation here during the Great Patriotic war of immigrants, which predetermined the principles of subsequent intercultural integration.

The pedagogical team of the school creates and develops the practice of conducting an educational process which is realized by the school "individually" by each teacher, through the general and individual system of work with schoolchildren: the administration, class teachers, parents, subject teachers, a psychologist, speech therapist and social pedagogue.

Regarding the subject of attention for the school and the purpose of consideration in this article the authors see the problem as such: how to show clearly and practically 
in a material way, how and on the basis of what exactly students, as they learn and develop their personality in the school over time, adapt and develop in a new environment? How do foreign students develop from elementary school until they take their graduation exams (EGE)? How does this process "mold" a child into a respectful and well-educated young citizen of the Russian Federation?

Often, the family of the future first-grader prepares him or her for school by promoting it as an interesting and exciting life, a chance to make new friends, to look forward to going to school and meeting their teacher. All this is normal and usually "packed" as a holiday, because, first of all, for the future first-grader this is an entry into a more complex, more "adult" life for him or her. The atmosphere of pre-holiday preparation for school and the holiday itself, joyful discoveries of new and educational games sooner or later comes to an end, and workdays come, and the child studies and learns a lot of new things. It is interesting and sometimes not easy (because "A cat with gloves catches no mice" - the results require effort). This version of the expected stress in every Russian family is experienced in its own way, but sooner or later such adaptation comes.

Regarding children coming to this school from a completely different language environment and culture, often without the knowledge of the Russian language, their family members are not able to provide effective assistance, because parents at home prefer to communicate with the child and with each other in their native language. This category of children replenishes the classrooms of the educational institution we are considering every year, which also certainly creates a stressful situation. Such children, upon coming to school, experience a real "cultural shock".

The formation of a child's two languages simultaneously is a complex process that requires some effort, patience, support, and attention of parents, but at the same time and contrary to many stereotypes, does not require the involvement of specialists. The results of this situation for such children are often obtained "at the exit", at the end of school. It is very interesting that although belatedly, this category of children makes a qualitative leap in development. They are less sick than others, relatively more flexible, psychologically plastic. Not all and not one hundred percent of course, but as a result, they are a little more successful in communication.

The real percentage of such children for the school over the last five years was as follows: in the 2014-2015 school year with a total of 620 students, $7.5 \%$ were foreign students, in 2015-2016 out of 694 students, they made up 7.3\%, and in 2016-2017 of 767 students they comprised 6.3\% and in 2017-2018 as of the month of December, of 780 pupils, $7.2 \%$ were foreign. These are all schoolchildren for whom Russian is not their native language. Most of them, i.e. more than 50\%, did not speak Russian at all when they entered primary school and in addition, there are always students in the middle level who come to this school at different times. These are different from ages, so their adaptation is also different.

The subject of our attention is these students because it turns out this initial inevitable stress is a significant step in fostering the development of additional potential in foreign students (during the entire period of formation of the individual from child to young adult) based on secondary school. Russian language for them acts in two ways, as a problem to be overcome and as salvation and later worthy way out.

The educational institution takes purposeful steps in an attempt to significantly develop and strengthen the study of the Russian language in all age groups. Russian provides them a way to think, develop and discover new perspectives in their lives. 
It also gives them a way to better understand others and develop the nuances of understanding human nature that can never be formalized.

During the process of socialization, a child goes through all stages of the evolution of society's thinking, and the social group develops within itself a special type and style of thinking. Language in this sense is not just a means of communication, but also an instrument for interpreting a special cultural environment and its characteristic way of thinking. For a child originally from one cultural environment who enters another, this process acquires the features of variability. This tempers the child in a stressful situation. It reveals the potential of his or her intelligence and thinking becomes more flexible.

In this context, it is interesting to preserve the Russian language and culture of immigrants of the first wave (often referred to as white emigrants). It is widely known about immigrants in the West (France, USA, Australia, etc.). However, even in the Far East, in China, Russian emigration through the preservation of language and culture occurred at least until the end of the Second World War. It also became one of the centers of attraction for other ethnic groups who emigrated from the territory of the Russian Empire. According to E. V. Yakovkina: "the national composition was represented mainly by Russians, as well as Ukrainian, Belarusian, Georgian, Buryat, Tatar, and other national communities." (Yakovkin E. V. Russian Soldiers of the Kwantung Army / E. V. Yakovkin. - M.: Veche, 2014. P. 10-11)

It is their first language and manner of thinking from another culture which gives foreign students a unique advantage in self-actualization and finding their identity in a different culture. This is awareness and self-realization through the interactions between different ethnic and social groups. On the other hand, it is unique to the individual and can create certain problems for children who are just beginning their life paths, such as self-identification and finding their place in the world.

"... An example with no more than $7.5 \%$ of foreign students making up the contingent of pupils of educational institutions, proves that a reasonable and balanced inclusion of children with different cultural and linguistic code in the new environment proves to be effective, and limits the formation of certain cultural enclaves which could lead to destructive tendencies in society, and at the same time, allowing their best,... adaptation in the context of "finding themselves", and their most efficient integration. (see, for example, Kalashnikova, E. M. Personality and Society (Identification Problem): monograph. - Perm: Perm State University Publishing House 1997.-156 p.)

Junior (primary) school - primary ZUNs (Knowledge, Skills and Attitudes) are created, i.e. through play and various forms of activity, differentiation, children master the skills of existence among peers and the ability to learn. The interaction of the school with them and their family creates options for a child-adult community in micro-class groups. A teacher is someone who does a lot for children but seldom considers what can be had from the student. The main thing here is that not only knowledge is shared, but a worldview, and this really means a lot! Within the framework of the formed educational environment, it is necessary to purposefully restore the priority of human communication, which represents well-known difficulties in the world, in everything and everywhere (digital communication, and click or clip) thinking on a global scale.

Secondary school (adolescence) is a period when, in addition to the main educational tasks, children are actively socializing in the outside world, finding their place in different societies, learning how to dialogue, communicate, cooperate and 
develop their skills of self-expression. The requirements for all are the same: training is conducted according to a textbook and programs, there are no differentiated tasks for control works, but the teacher has to solve the problem of equalization.

The basis of work with middle-level students are individual and differentiated approaches, periodically and at all stages of the lesson and, of course, over time. In this situation, dealing with the identified problems face to face, the literature teacher is forced within the framework of the program to make maximum use of the available methodological material. A constant search is conducted for effective means of influence, forms of work and development of various principles of organization of educational activities for such classes.

High school (young adults) - students consciously learn to look for and choose profiles and individual trajectories of their own development and prepare for final exams. They specialize in tests and practice ("to understand what exactly is not mine"), they take part in training programs, try to look for and determine themselves in a chosen field. After all, education in the broadest sense is not about "cramming" some knowledge into your head just to pass exams... Education for a young person is about how to find your place in the world, to do something useful, to lessen conflict in life or experience, and to rejoice more. And for this it is necessary to understand something about the world, and how it progresses and changes.

The teaching staff at the school should create educational conditions for learning and a favorable environment for the development of the general culture of each child, the skills for working with the flow of information, the culture of thinking. We do not need so much to lead the student "by the hand", as to show him or her what and how it is better to do, to support, empathize, and help to look for individual ways and solutions, and thus, in this process to know ourselves. The key points here and directions are the figure of the teacher, traditions, and practices in the everyday life of the school, as well as the whole atmosphere of the relationships being built.

A. Einstein said: "the Purpose of the school should be the education of a harmonious, developed personality, not a specialist...". At school, we do not just teach our students, but first of all - we create the conditions in which they learn. An attempt is made to create an environment and a General cultural orientation of our educational process. In fact, we need to give birth to a young person who will move forward, and he or she will receive knowledge in parallel with integration into society.

The main result of school education for us is its compliance with the goals of the advanced development of young people. Our students should study not only the facts of history, the results and world achievements of today or the past development of mankind. They must prepare and be able to meet the challenges and methodologies that, although not clear to us today, will be faced in earnest tomorrow, and they will have to face them on their own and in a responsible way. The world around us is changing too dynamically and qualitatively, and this obliges us to take into account the reality and act ahead of the curve, and such readiness in graduates is necessary for society in the very near and foreseeable future.

A key feature of modern school education is the introduction of a model that assumes high flexibility, relative to the analytical apparatus. The younger generation must learn to respond to ever-changing conditions and updated information, embedding it in the already existing system of values and guidelines. Otherwise, a person just accepts the facts as they are, and as a consequence, his or her personal opinion and evaluation are lost under the mass of various clichés, stereotypes cultivated by the environment. The opportunity for constructive reflection is lost. In 
this case, each person has to pass the path of growing up independently, which is relevant for elementary, middle school, as well as high school. Faced with urgent educational and everyday problems, the person imperceptibly acquires certain features and individual traits.

If a person is initially in an environment in which his social well-being depends on the ability to build communication, and the information society is just such a model. At the same time, it is logical to assume that a person with such a skill will be more successful, more competitive, and possess the ability to solve non-trivial tasks.

In the process of socialization in the ever-changing world of such a person, a modern school is necessary, one that allows the potential of such a person to be revealed to the fullest. Thus, in addition to paperwork and the exhausting and upsetting ongoing work of teachers, the modern school faces an extremely important and difficult task - to determine what exactly will be in demand by society in the near "future" and why, and most importantly, to implement it, i.e. to ensure the formation of orientation and implementation of such aspects of social activity as:

"Digitalization" of all spheres of our life

Robotization, as in the increase in automation in everyday life, industry and the economy

Globalization of knowledge, economics, and technology. We are now learning to think at the level of the whole world, planetarily, but at the same time, we risk losing our identity and culture...

Ecological thinking, where everyone in this world sees themselves as part of the ecosystem and something greater, where people, one way or another, affect the entire ecosystem of our planet

Demographics, changing labor markets, and the ability to learn or retrain throughout life

A global community network, where everything is connected to a single network and everything becomes more flexible, simplified (bureaucratically) and selforganizing.

Socio-technological acceleration in a world where a single person is physically unable to keep up with the volume of information and awareness of all changes, and learns to assess the risks: " "risk-oriented thinking' is the ability of the individual to determine the situation from the standpoint of risk, identify, analyze and assess the risk, while having the willingness to influence the risk in order to obtain a positive result, including the safety of life" (Dolinina I. G., Kushnareva O. V., Formation of occupational safety culture based on the development of risk-oriented intelligence of students//International Journal of Environmental and Scientific Education).

To study the situation in a particular educational institution, we carried out experimental and practical work in school № 36 in Perm. In many ways, the actual results of our research reflect modern social needs (Annex 1)

Based on the results, we can see what are universal examples and what is specific to a particular school.

Our President says: "In Russian, we think, express our worldviews, communicate and perceive all information. But a wise, balanced and meaningful language policy is perhaps the most difficult, delicate and important condition for preserving the integrity of a multi-ethnic state, society and the unity of all the people, the transmission from generation to generation of foundations, traditions, and values... All the wealth of the Russian language, its inexhaustible possibilities, is a gold reserve, which must be valued and fully protected. The higher the level of knowledge 
and use of language in society, the higher the culture of speech, the more powerful the intellectual level of the nation, and the greater the potential for its development. Having a specific identity attached to primitive language almost always reflects a primitive way of thinking. Conversely, the possession of figurative, bright, literary and competent speech dramatically increases the competitive advantage of a person, the height of his position on the social ladder, and simply determines his General culture..." (from V. Putin's speech at the Joint Council on the Russian language in Moscow on 19.05.2015 / / http://kremlin.ru/events/president/news/49491).

Russian is the state language of our country, the language of international communication. It was the Russian language, in fact, together with culture, that formed Russia into a single and multinational civilization, and for centuries it has ensured the connection of generations, continuity and mutual enrichment of ethnic cultures. We are aware that all the information, cultural and state unity of the country, the unity of the entire Russian people directly depends on the development of our young people's national language, and on the state and spread of the Russian language.

In our problem, the Russian language is a key link and the basis for the creation of a school environment for children to communicate and their immersion (entering the culture of the ethnic group: participation in scenes on holidays, tongue twisters, and deciphering ties semantic ties are usually relevant) as the basis for their adaptation to the school environment.

Foreign children see Russian in a particular way, in that they perceive the grammar rules of the Russian language through the prism of their own, and they transfer the phenomena of their native tongue into the Russian language, which often leads to errors. The first task of the teacher here is to overcome the influence of the native language so as to prevent interference errors in Russian speech. For some children, the characteristic behavior is the desire to isolate and withdraw into themselves, to limit their circle of communication solely on a national basis, to rely on the customs, traditions and moral and ethical norms of their ethnic group (Sukhanova E. Technology and methods of teaching the Russian language in multiethnic classes// https://xn--j1ahfl.xn-plai/library $/ \%$ C2\%ABtehnologii_i_metodicheskie priemi_obucheniya russkom_1 63757.html).

From J. Huizinga's point of view, we initially, at the earliest stages of our socialization, learn to try on certain roles, setting rules, seeking to idealize all possible situations of social relations, and over time, we seek to expand and implement this ideal image. "Within the playing space, there is a perfect order inherent only to it ...a positive property of the game: it establishes order and it is order itself. In this imperfect world, in this life of turmoil, it embodies a temporary, limited perfection" (Huizinga, J., Homo Ludens. Articles on the history of culture. - M.: Progress Tradition, 1997. - 416 C, p. 39). A "communication game" creates the illusion that we are turning into somebody else, which in the case of a crisis situation is to suffer, to take responsibility for the failure in the performance of the task: "Someone who is disguised or wearing a mask is a different creature. But he "is" it's different being" (Huizinga, Th. Homo Ludens. Articles on the history of culture. - M.: Progress Tradition, 1997. -416 C, p. 43).

Foreign students in the process of delving into the peculiarities of the Russian language initially see it as a game and thanks to this approach find playful ways to learn. In the future, this skill is subconsciously extrapolated to the rest of their 
activities. They turn out to be more receptive and adaptive to the changing "rules of the game" than those who were initially immersed in its atmosphere and gradually mastered its rules. The fact that foreign students are jointly developing a non-native language for themselves, to join the new culture, where many of the features are not clear, creates a synergistic effect. Each of them brings his or her vision of a new cultural code, passing it through themselves (because it is the only way to understand and comprehend something new), thereby exchanging what is seen and heard with other foreign students, who are also motivated to learn a new language, and creating a general picture of reality. The latter turns out to be more robust and complex than each of the individual pictures created by the consciousness of an individual child. This cultural interpretation - the perception of the norms and customs of the new ethnic group through the prism of the previous cultural foundation can be transferred to any new knowledge later in life.

The skills of language and literature teachers, whose participation becomes necessary at a certain stage, are not only directed by the speech and correctness of pronouncing sounds but in establishing communication between a sound and interpretation of meanings, in some kind of hermeneutical act opening a new horizon of thinking for a young foreign student. The horizon of thinking is considerably expanded through accurately placed mental accentuation - that is in each sense, key for understanding the new environment, has to be placed strictly in the place allocated for it, leaving, however, an opportunity for its deeper judgment or even replacement in the course of further development of new culture in the growth process of a foreign student. For such a student, interaction with native speakers becomes at the same time both criterion of the validity of the received knowledge and a less formal way to dig deeper into its features. The last assumes also the existence of more difficult reflection which includes not only the specific representative of the other language environment, but also the external observer, for example, the teacher, another foreign student, who help him or her in their own interpretation of events not only from within, but also from the outside, to understand at the spontaneous level, but also in time, the multistage reflexive analysis of a situation. In other words, the cognitive act and its results.

Thus, for these children, the first stage of adaptation, in addition to simply immersing in the environment, is learning Russian. They study it for their successful socialization and subsequent mastering of all disciplines. The period of relative or complete mastering of Russian varies by individual. It varies from 4 to 12 months but this is true only for children aged 7-9 years; in all other cases, the degree of variation increases and is difficult to systematically analyze.

The task of the teacher working with foreign students is not limited to the learning of language forms, turns of speech or linguistic designs, but also to nurturing skills for an analytical reflection into a mental matrix of the socialized subject, in order to give the child from another language environment the chance to learn to realize the advantage.

The main objective of teaching Russian as a foreign language is to create a multidimensional language environment. A simple lesson is clearly not enough. It should include the prevention of mistakes in the accuracy of statements and in speeches, involve an atmosphere of play and activity It should also explain the sense of implications or metaphors and foster an academic mastering of the main standards of Russian as a priority for polycultural education. 
The timely and correct work of the teachers who teach foreign students Russian is hampered in various ways. The heterogeneity of Russian language proficiency among children of foreign students studying at the same time in the same class. This is also true among children for whom Russian is their native language, especially for academically weak classes or specific lagging children.

A Russian language teacher who teaches children with difficulties in mastering the Russian language usually has a standard pedagogical education that focuses on teaching Russian to native speakers. Therefore, for such a teacher it is not an easy task to develop a plan for both the foreign and native students with both an individual strategy and pedagogical impact. The educational activity can be in the form of collective games, working with children in pairs, with cards, and chain as well as individual work.

A variety of issues are taken into account. Individualized cards are created which make a note of his or her support or lack of assistance from parents, speech therapy issues and their complexity, psychological characteristics, dynamics of behavior and performance, motivation, ability, and the emotional and overall activity of each of the children. The work of a speech therapist is almost always necessary with such children since speech therapy issues almost always directly affect the success of classes. But as they are smoothed out there is a gradual breakthrough in learning, and children begin to learn more easily.

Foreign students who delve into the peculiarities of the Russian language initially perceive it all as a game, and this, in addition to their age, contributes to how they deal with it. This skill is then subconsciously extrapolated to the rest of their schoolwork. They turn out to be more adaptive to the changing "rules of the game" than those who were initially immersed in Russian and gradually mastered its rules.

The foreign student along with their native classmates learn a new culture, many of the features which they are not clear, thereby creating a synergistic effect. All of them bring their own vision of a new cultural code, passing it through themselves (because this the only way to understand everything new), exchanging what they saw and heard again with other foreign students who are also motivated to learn a new language, and creating their own picture of reality. The latter turns out to be more complex and multi-layered than each of the individual paintings created by the consciousness of an individual child. Such cultural interpretation - the perception of the norms and customs of the new ethnic group through the prism of the previous cultural foundation in later life can be transferred to any new knowledge.

The professionalism of the speech therapist, whose role becomes necessary at a certain stage, is not just to help students speak and pronounce words correctly, but also to establish a connection between sound and the interpretation of meanings, in particular, the act sets new boundaries of thinking for young foreign students. This thinking continuously expands due to mental accentuation. Each thought is crucial for understanding the new environment and has to be placed strictly in the place allocated for it, leaving, at the same time, an opportunity for its deeper judgment or even replacement in the course of a further judgment of new culture in the development of the foreign student. Interaction with native speakers for it becomes at the same time both criterion of the validity of the received knowledge and way of less formal penetration into its features.

The issue of increased capacity for reflection, developed since childhood in the ability to account for all their actions, analyze their thoughts and take specific steps, 
as a result, can be considered the key competitive advantages of a person from a different linguistic environment.

\section{Research interests}

Children who were born and raised in the native cultural environment do not feel the need of understanding what they say or do at the level required of foreign students. They often act spontaneously, and so their ability to engage in constructive introspection, in this sense, is a priori below.

According to I.A. Sykalov, "...to a greater extent, cultural studies are interested in spiritual values and basic norms" (Sykalov I. A., Sociology of law in the context of empirical studies of law: problems of FORMATION, POSITIONING AND INSTITUTIONALIZATION. Prison system and society: the experience of interaction proceedings of the VI International Scientific and Practical Conference. Perm, 2019. P. 180.). For this reason, the training of foreign students becomes the object of not only teaching but also cultural exposure and analysis. In this respect, cultural studies are directly related to the study of value-rational behavior.

A child from another culture is forced to pass through a stream of new information. Imbued with it at all levels of perception: emotional and volitional, and in concrete and abstract thought, the student receives and develops this skill to a greater extent. This means that he or she learns to better understand life, and is less upset about the little things or because of failures and so is less likely to be drawn into all sorts of conflicts. This is a kind of "vaccination by common sense", and it creates a quality of life for this student as a representative of a different language environment.

We developed a questionnaire as a method of practical support. (Annex 1)

The survey was conducted among primary and secondary school students between the ages of 7 and 16. Participants were given the opportunity to remain anonymous.

In all, 300 students were polled and of those 75 were foreign students.

The nationalities represented were Armenians, Azerbaijanis, Kyrgyz, Tajiks and other representatives of the peoples of the near abroad.

During their time learning at school, $95 \%$ had mastered the Russian language.

$5 \%$ had not fully mastered the language.

Socialization of the enrolled foreign students during the study period was $100 \%$ :

1) $68 \%$ started school with a zero level of proficiency in Russian

2) $25 \%$ fully mastered Russian in preschool

3) 7\% were bilinguals (who spoke their ethnic group's language and Russian)

Overall, students soberly assess their knowledge of the language. Many children openly declare their illiteracy. And some of them want to eliminate this drawback.

During the survey we encountered the following statements regarding the Russian language:

"I am proud of my language". (native Russian speaker)

"I think that the Russian language can become an international language".

"Well, Russian mixed with English is not good". (native Russian speaker)

"I would like Russian to be used everywhere".

"It is like all other languages. I love Russian. It sounds beautiful".

"It's very good. I grew up here in Russia and got used to the Russian language, although I speak Armenian at home". 
The prevailing attitude towards the Russian language was predominantly positive, including among those who did not consider it their native language. No negative statements about the Russian language were found in the questionnaire.

\section{Conclusion}

Based on the data obtained, we can conclude that the attitude to the Russian language among foreign speakers is characterized by a high degree of loyalty. Children are ready to learn Russian, to accept cultural traditions typical for the overwhelming majority of Russians, and in general, are focused on successful socialization in Russian society and presumably assimilation of the basic national and ethnocultural values.

1. The relatively small percentage $(7.5 \%)$ of the total student population, contributes to foreign students' ability to "melt" or bond in order to master aspects of a new culture and community through language and discourages them from creating national, religious or other countercultural social groups.

2. Children from 7 to 8 years of age learn Russian sufficiently from zero (this varies by individual), usually within a calendar year. The learning process, as a rule, progresses at the same rate to the end of primary school. According to Russian language survey cards of all children in school about their attitude and understanding of the Russian language, children from 9 to 11 years of age (from 2nd to 4 th grades) are relatively the same in their knowledge and general understanding of the Russian language: in understanding the meaning of words in the classroom, on TV, in textbooks and in literature. Children are aware of the degree of their literacy, the problems in the development of subjects in school, and know and see ways to resolve possible or real difficulties. From the point of view of developmental psychology, these results fit into the systematics of sensitive periods in personality development.

Society should accept and integrate representatives of a different language environment and ultimately give them the opportunity to realize their full potential. One of the problems of modern society is the simulation of the connections and relationships that exist between people. There are many reasons for this, but the main one is information overload and the impact of this vast amount of information on each of our minds and the already mentioned problem of differentiation and integration of society. On the one hand, every person is connected with the entire world through social networks, television and the press. On the other hand, everyone is isolated and real live communication is replaced with merely a surrogate. In these conditions, which can still be called, a "communication game", the foreign students, well integrated into the social environment, have a number of advantages. The "communication game" becomes a specific way to absolve themselves of responsibility for their words and actions that modern man is keen to avoid, as well as reducing the number of possible risks, depriving themselves of a cause for fear" (Freud, Z. Psychology of the Unconscious. - Moscow: Education, 1989. - p. 448, SS.386-390).

In recent years, in the school we have monitored, we have seen many real-life examples of graduates, who started school as foreign students and have left our school and have now entered an independent life. These graduates often go on to become bright personalities. They are pleased with the teaching staff and leave teachers with 
the belief that all their efforts and work were not in vain, and that the school environment is effective and tested annually by life itself.

\section{References}

1. I. G. Dolinina, O. V. Kushnareva, Formation of occupational safety culture based on the development of risk-oriented intelligence of students, International Journal of Environmental and Scientific Education

2. Z. Freud, Psychology of the Unconscious (Education, Moscow, 1989).

3. J. Huizinga, Homo Ludens. Articles on the history of culture (Progress Tradition, Moscow, 1997).

4. A.V. Ivanov, the Phenomenon of the cultural environment of educational organizations in the development of children's spiritual values, Pedagogical education in Russia, 3, (2016).

5. E. M. Kalashnikova, Personality and Society (Identification Problem): monograph (Perm State University Publishing House, Perm, 1997).

6. V. Putin's, Speech at the Joint Council on the Russian language in Moscow on 19.05.2015 / / http://kremlin.ru/events/president/news/49491

7. E. Sukhanova, Technology and methods of teaching the Russian language in multiethnic classes. https://xn--j1ahfl.xn-p1ai/library/\%C2\%ABtehnologii_i_metodicheskie_priemi_obucheniya_russko m_163757.html

8. I. A. Sykalov, Sociology of law in the context of empirical studies of law: problems of FORMATION, POSITIONING AND INSTITUTIONALIZATION, Prison system and society: the experience of interaction proceedings of the VI International Scientific and Practical Conference. Perm, 2019.

9. V. I. Teterin, Internationalization of higher education as a way of communication in the modern educational space (using Perm universities as an example), Problems of Modern Pedagogical Education, 55-11 (2017).

10. I. G. Dolinina, O. V. Kushnareva, Formation of occupational safety culture based on the development of risk-oriented intelligence of students, International Journal of Environmental and Scientific Education

11. E. V. Yakovkin, Russian Soldiers of the Kwantung Army (Veche, Moscow, 2014). 